\title{
Vascular tissue engineering: biodegradable scaffold platforms to promote angiogenesis
}

\author{
Janna V Serbo' and Sharon Gerecht*2
}

\begin{abstract}
The ability to understand and regulate human vasculature development and differentiation has the potential to benefit patients suffering from a variety of ailments, including cardiovascular disease, peripheral vascular disease, ischemia, and burn wounds. Current clinical treatments for vascular-related diseases commonly use the grafting from patients of autologous vessels, which are limited and often damaged due to disease. Considerable progress is being made through a tissue engineering strategy in the vascular field. Tissue engineering takes a multidisciplinary approach seeking to repair, improve, or replace biological tissue function in a controlled and predictable manner. To address the clinical need to perfuse and repair damaged, ischemic tissue, one approach of vascular engineering aims to understand and promote the growth and differentiation of vascular networks. Vascular tissue engineered constructs enable the close study of vascular network assembly and vessel interactions with the surrounding microenvironment. Scaffold platforms provide a method to control network development through the biophysical regulation of different scaffold properties, such as composition, mechanics, dimensionality, and so forth. Following a short description of vascular physiology and blood vessel biomechanics, the key principles in vascular tissue engineering are discussed. This review focuses on various biodegradable scaffold platforms and demonstrates how they are being used to regulate, promote, and understand angiogenesis and vascular network formation.
\end{abstract}

*Correspondence:. gerecht@jhu.edu

${ }^{2}$ Department of Chemical and Biomolecular Engineering, Johns Hopkins Physical Sciences - Oncology Center and Institute for NanoBioTechnology, Johns Hopkins University, Baltimore, MD 21218, USA

Full list of author information is available at the end of the article

\section{Introduction}

The ability to create, repair, and regulate the human vascular system holds wide therapeutic applications. Scientists have attempted to harness this ability for treatments in myocardial infarction, ischemia, peripheral vascular disease, and wound healing [1-3]. There is a need to stimulate vascular growth and repair, such as in ischemia and tissue-engineered constructs. Specifically in cardiovascular diseases, vasculature must be repaired because ischemic tissue has been deprived of oxygen, leading to cell damage and cell death [2]. Cardiovascular disease was named the leading cause of death globally in 2004 and also the number one cause of death in the United States in 2010 [4-6]. Along with other vascular diseases, it continues to drain billions of dollars in healthcare costs from the economy [6].

Grafting autologous arteries and veins to bypass a blocked and damaged vessel is currently the most common clinical solution for a heart attack caused by atherosclerosis $[1,7]$. The problem with bypass surgery is that it does not repair the damage caused to heart tissue by ischemia and hypoxia, and most patients do not have healthy vessels for grafting due to their current disease or advanced age [7-9]. There is thus a significant clinical need to perfuse and repair damaged, ischemic tissue by promoting the growth of new vascular networks through angiogenesis, the sprouting of blood vessels from preexisting vasculature, or through vasculogenesis, the spontaneous formation of new vasculature without the presence of pre-existing vessels $[10,11]$. Vascular tissue engineering studies the formation and growth of vascular networks through the utilization of scaffolds, varying cell sources, growth factors, cytokines, and mechanical stimuli to recreate a physiological microenvironment. Specifically, scaffold platforms that are fabricated from various biomaterials enable control over vascular network development through the regulation of different scaffold properties, such as composition, mechanics, degradation, and dimensionality. This review focuses on various biodegradable scaffold platforms to control vascular network assembly and promote angiogenesis. Following a short description of the mechanisms of vascular network formation and blood vessel 
biomechanics, the key principles and cell sources for vascular tissue engineering are discussed.

\section{Background}

Vasculogenesis and angiogenesis

During embryonic growth, new vasculature develops through vasculogenesis. Angioblasts differentiate into endothelial cells (ECs), which cluster to form a tube-like structure supported by smooth muscle cells (SMCs) [10]. ECs create the selectively permeable lining of blood vessels, forming a barrier that resists thrombosis and facilitates platelet activation, especially during wound healing. By producing collagen and elastic fibers, SMCs provide contractile and elastic forces, which support blood vessel integrity. After initial blood vessels form, the vascular network continues to grow through a process called angiogenesis, which is particularly important during natural wound healing and also during cancerous tumor survival. The extracellular matrix (ECM) has a diverse composition that helps regulate angiogenesis by providing critical signaling cues, EC receptor interactions, and the retention of growth factors [12-17]. During this process, proteases degrade the ECM to make way for new vessel formation.

In angiogenesis, vessel branching generally occurs in three stages: quiescence, activation, and resolution [10]. During quiescence, EC proliferation is inhibited as ECs are tightly interwoven with vascular endothelial cadherins and are supported by pericyte cells. Activation usually occurs when a vessel receives angiogenic signaling cues, such as vascular endothelial growth factor (VEGF), from another cell source. Upon activation, pericytes break away from the basement membrane. The basement membrane degrades, allowing room for extending ECs to migrate [10]. The EC monolayer dilates as the vessel's permeability increases by VEGF signaling, and cell junctions become less tightly bound. A tip cell, an EC with filopodia that is chosen to sense the microenvironment, leads the direction of vessel formation. This tip cell extends from the degraded basement membrane with the help of directional cues from angiogenic factors $[10,16,18]$. The surrounding ECs are known as stalk cells, which support the tip cell, proliferate to lengthen the extending stalk, and eventually form a new vessel. During resolution, the extending tip and stalk cells fuse with another extending vessel branch. EC junctions are reformed, and pericytes reattach to newly laid basement membrane [10].

\section{Key biochemical molecules in angiogenesis}

Key biochemical molecular players in angiogenesis are VEGF, angiopoietin-1, platelet-derived growth factor, and some fibroblast growth factors (FGFs), such as basic FGF (FGF2) and FGF9 [10,12,18-21]. VEGF is an important stimulator of angiogenesis [18,19,22-26]. FGFs play a role in vessel sprouting and in mural cell wrapping for support $[20,21]$. Platelet-derived growth factor plays a role in stabilizing new vessels by recruiting mural cells [21]. Tip cells are said to migrate toward increasing VEGF gradients, and angiopoietin-1 is said to stabilize stalk cell formation [18]. More detailed information on the role of angiogenic molecules and the signaling pathways involved can be found in the reviews by Carmeliet and Jain [10], Cheresh and Stupack [13], and Witmer and colleagues [26].

\section{Mechanical forces and oxidative balance}

Blood flow and pressure act on the blood vessel wall to maintain homeostasis through biochemical pathways and mechanical forces. Wall shear stress and circumferential wall stress and strain are the main forces associated with vascular wall biophysical regulation [27,28]. Wall shear stress results from the frictional force of blood flowing past the EC layer. Circumferential wall stress and strain (stretch) in the circumferential direction result from pressure. This pressure is generated by pulsatile blood flow and acts perpendicular to the EC layer [28]. In physiological and pathological states, the vasculature can be dilated and remodeled by changes in blood pressure and flow.

Oxidative balance is key to maintaining healthy vascular function and homeostasis. Blood pressure causes vessels to stretch beyond their relaxed state, known as mechanical distention. Shear stress caused by blood flow activates integrins on the EC monolayer and induces vasodilation. Integrin activation leads to endothelial nitric oxide synthase phosphorylation. Activated endothelial nitric oxide synthase produces nitric oxide, which stimulates vasodilation, relaxes SMCs, and decreases blood pressure $[27,28]$. To counterbalance vasodilation and induce vasoconstriction, circumferential stretch leads to nicotinamide adenine dinucleotide phosphate oxidase activation that generates superoxide, increasing free radical levels [28]. Free radical anions react with nitric oxide to create peroxynitrite, an oxidant. The decreased levels of nitric oxide reduce vasodilation. Oxidative balance between free radical species (oxidants) and antioxidants, such as nitric oxide, controls the vasodilation and homeostasis of the vascular wall [28]. In tissue engineering, this balance is important to take into consideration when designing solutions to repair vascular damage.

\section{Vascular tissue engineering: cell sources for regenerative medicine}

In vascular regenerative medicine, there are two focuses: forming artificial blood vessels, and producing tissue constructs that regulate the growth of new vascular networks. Both of these approaches to repair, improve, and understand the human vascular network are founded 


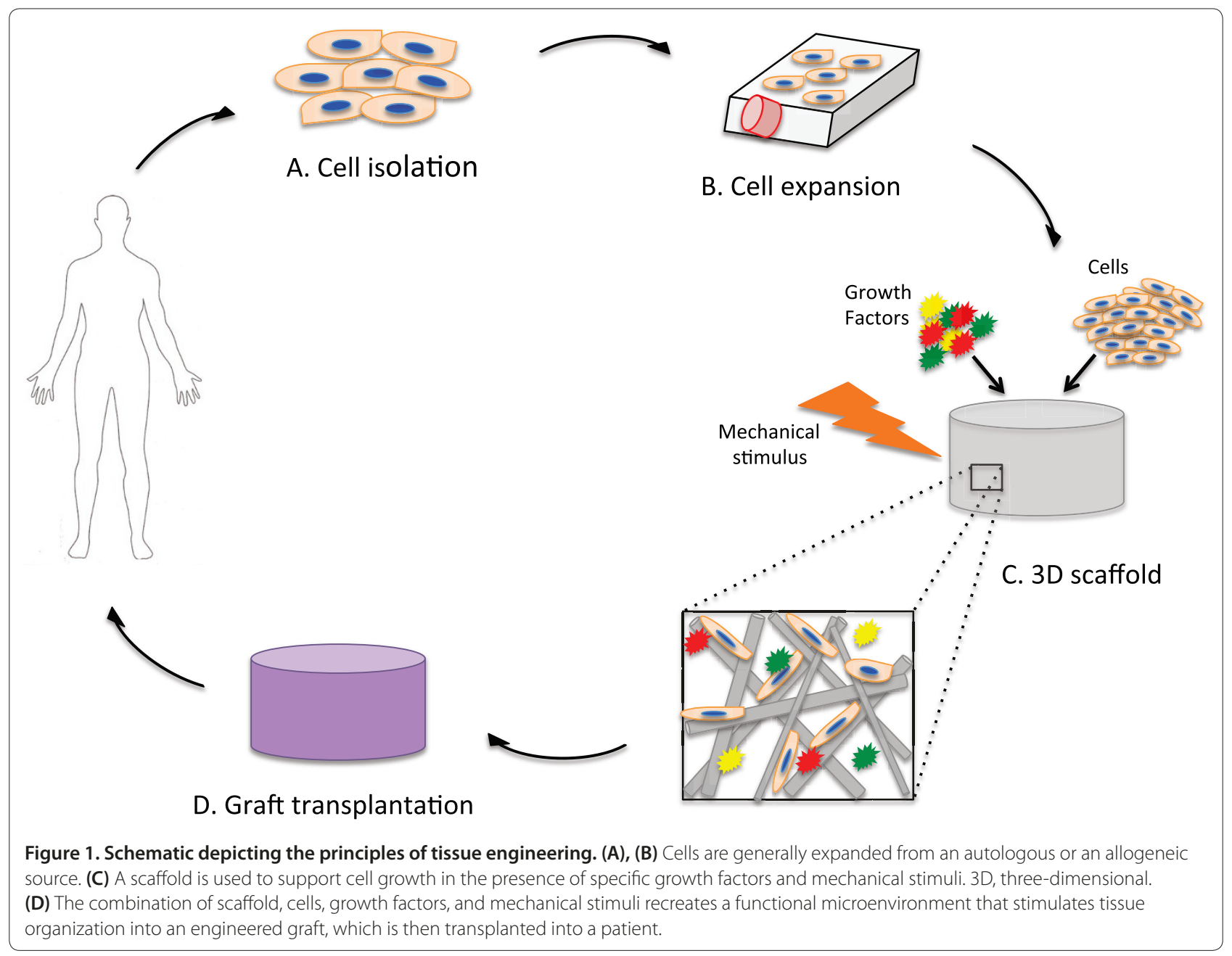

in the principles of tissue engineering. Generally, the components used in vascular engineering are a biodegradable scaffold, cells from either an autologous or an allogeneic source, and growth factors necessary to create a stimulating microenvironment, as depicted in Figure 1 $[7,9,29]$. Many grafts and constructs are also preloaded in vitro by mechanical stimulation in a bioreactor, which mimics physiological conditions $[1,7,8]$. Researchers use various combinations of these components to try to recapitulate human vascular function.

Cell sources for tissue engineering can be divided into three categories: somatic cells, adult progenitor and stem cells, and pluripotent stem cells (PSCs). In these categories, there are numerous cell types that are used for vascular tissue engineering. For further details please refer to current reviews by Bajpai and Andreadis [30] and Reed and colleagues [31]. Briefly, some common cell sources used for vascular constructs are ECs, SMCs, endothelial progenitor cells (EPCs), mesenchymal stem cells, and PSCs [30,31]. For mature vascular cells, ECs and SMCs can be derived autologously, directly from a patient. The use of autologous cells can be ideal for vascular engineering because there is no immunogenic response or cell rejection upon implantation. However, mature vascular cells are terminally differentiated with limited proliferation capacity and thus limited expansion ability $[8,9]$.

Adult progenitor cells have more proliferation potential and plasticity to differentiate down a specific lineage. EPCs can be isolated autologously from peripheral blood and bone marrow [11,32,33]. However, these cells have limited self-renewal capabilities compared with stem cells, and their origin and regeneration capacity are debated. Adult stem cells, such as mesenchymal stem cells, are an autologous multipotent cell source that have high proliferative capacity, can differentiate into SMCs, and have been suggested to be able to differentiate into ECs [30,34-39]. Nevertheless, autologous adult progenitor and stem cell populations can be sparse and difficult to detect and isolate. As such, methods for isolating and expanding autologous EPCs and mesenchymal stem cells are generally time intensive and expensive [9]. 
PSCs, including induced PSCs and embryonic stem cells (ESCs), can differentiate into all three germ layers. They have an unlimited ability to self-renew, making them easy to expand for therapeutic use [40,41]. ESCs are derived from a developing embryo, while induced PSCs are generated by the reprogramming of somatic or adult progenitor and stem cells. Allogeneic cell rejection is therefore a consideration when developing ESC-based therapeutics, while induced PSCs hold the potential to be a useful autologous cell source [40]. Human PSCs have been successfully differentiated into mature and functional vascular ECs and SMCs [30,31,42-56]. Therapeutically, the use of human PSC vascular derivatives has oncogenic concerns, such as teratoma formation due to proliferative or undifferentiating cell populations [56,57]. Allogeneic cells either from healthy donors or from animals can make cells available via an off-the-shelf route, as cells can be expanded beforehand in large quantities. However, there are problems with graft and construct rejection due to the foreign allogeneic cells, as well as differences between donor and recipient cell characteristics such as age, antigens, and proliferation potential.

\section{Biodegradable scaffold platforms to promote angiogenesis Scaffold materials}

The scaffold component is widely used in tissue engineering, especially to promote and regulate angiogenesis. Scaffolds were originally incorporated to give transplanted cells and the host's regenerating tissue a threedimensional support structure [8,9]. The scaffold mimics an in vivo cellular microenvironment better than a twodimensional monolayer, which is a common cell culture method in vitro. Researchers use scaffolds not only as a support for cell growth and differentiation, but also as an anchor to attach different bioactive molecules and signaling cues that enhance specific cell function. In the case of angiogenesis, molecules such as VEGF can be bound to scaffold surfaces, presenting pro-angiogenic signals to the surrounding tissue [23]. Among the different types of scaffolds, injectable scaffolds are a promising approach for promoting angiogenesis since they are less invasive than surgical implantation and can mold into oddly shaped structures to fill cavities and areas of necrotic tissue [58-60]. This review will focus on pre-formed or pre-constructed scaffolds to promote angiogenesis, but more information on injectable scaffolds can be found in Hou and colleagues [60].

A variety of materials are used for scaffold preparation, including synthetic polymers and derivatives of natural proteins. Synthetic materials are generally reproducible, cheap to fabricate, and readily available. This would make synthetic materials a probable therapy to translate clinically. Also, synthetic materials offer researchers control over many critical properties, such as the degradation rate and elasticity. Ideally, synthetic materials can be designed to degrade and resorb into the body at a rate that matches tissue regeneration and growth. However, a common problem with synthetic materials is that their degradation products can be toxic or can cause inflammatory responses, limiting scaffold success in vivo [9]. Natural-based scaffolds are generally derived from ECM components, such as collagen, fibronectin, and hyaluronic acid (HA). Researchers use scaffolds made from a single isolated ECM protein, combinations of ECM proteins, and decellularized ECM that was deposited by cells or extracted from a tissue sample or intact organ section $[16,17,61-66]$. Since ECM components naturally occur in the human body, ECM-based scaffolds support cell attachment, growth, and differentiation. They generally do not have harmful degradation products, making it easier to integrate with the body. However, with natural ECM-derived scaffolds, researchers have limited control over material properties such as the degradation rate, strength, and elasticity [9].

\section{Biodegradable polymer scaffolds: synthetic polymers}

Biodegradable scaffolds attempt to mimic numerous physical environments in the body. As such, they are designed to present signaling molecules and mechanical cues to cells and surrounding tissue, supporting cell growth, differentiation, and proliferation. Synthetic polyesters - such as polylactic acid, polyglycolic acid, poly(lactic-co-glycolic acid) (PLGA), and polycaprolactone (PCL) - are used extensively as scaffold materials $[9,21,24,67-69]$. These polyesters are usually inexpensive to produce, nontoxic, and degrade by natural hydrolysis in the body. Synthetic polymers can be synthesized with desired properties such as the degradation rate. This control makes possible the design of a scaffold that degrades at the same rate at which cell growth and tissue regeneration occur. However, synthetic polymers are limited in their ability to reproduce the complexity of the physiological, cellular microenvironment, as many biological components need to be added to replicate ECMdriven signaling.

Many researchers observe vascular network assembly using a three-dimensional, synthetic polymer scaffold to stimulate seeded cells. Lesman and colleagues co-cultured cardiomyocytes differentiated from human ESCs, fibroblasts, and ECs in a porous $50 \%$ poly-L-lactic acid (PLLA) and 50\% PLGA scaffold mixture to create a beating, prevascularized, muscle construct for application in myocardial infarctions $[2,68]$. The glycolic acid in PLGA decreased the degradation time of the scaffold, while PLLA provided an appropriate mechanical rigidity for cell culture. The polyester scaffold created a unique 
platform that allowed for successful vascularization and organization of synchronized, beating, cardiac muscle tissue. Later, Lesman and colleagues combined the 50:50 PLLA and PLGA scaffolds with a fibrin gel, which filled the scaffold's pore spaces [61]. When seeded with human umbilical vein ECs and fibroblasts or with human umbilical vein ECs, fibroblasts, and skeletal myoblast cells, this scaffold-gel mixture allowed for interconnected vessel-like network formation in vitro. The fibrin gel alone was not as successful because cell forces caused the softer gel to eventually shrink. These studies provided a unique fibrin, PLLA, and PLGA mixture for a scaffold that could successfully support vascular network formation. Des Rieux and colleagues combined nanoparticle technology with Matrigel ${ }^{\mathrm{ma}}$ hydrogels or with PLGA scaffolds [19]. An increase in angiogenesis was observed when encapsulated VEGF was incorporated into the PLGA scaffold, increasing local VEGF release. This study is one example of many approaches utilizing nanoparticle technology for vascular regeneration. Such approaches are aimed at targeted delivery to the site of injury followed by local release of pro-angiogenic factors, for the efficient localized retention of the therapeutic agent.

Singh and colleagues established a porous PCL scaffold platform with immobilized heparin on its surface [23]. Heparin's negatively charged sulfate groups attracted and bound VEGF's positively charged amino acids, leading to increased retention and absorption of VEGF in the scaffold. The heparin-PCL scaffold had high vessel density and increased endogenous angiogenesis upon implantation in NOD-SCID mice due to better retention and local VEGF delivery. In a following study, Singh and colleagues seeded human EPCs into heparin-PCL scaffolds and observed anastomosis of human EPC-formed vessels with mouse host vasculature after 7 days of subcutaneous implantation [24]. This platform improved growth factor retention and decreased leaching, utilizing heparin's negative charge properties. This approach thus holds the potential to alter other materials toward angiogenicpromoting properties.

\section{Biodegradable polymer scaffolds: natural polymers}

Natural polymer scaffolds are used because of their biologically recognizable side groups, which make them more compatible upon implantation and more likely to support cell function. Their composition, compatibility, porous structure, and mechanical properties make them suitable scaffold materials to mimic the natural ECM. Tengood and colleagues created a hollow, porous scaffold from cellulose acetate in the shape of a fiber that penetrated an in vivo site [21]. The scaffold's unique structure and pore size allowed for in vivo basic FGF and platelet-derived growth factor sequential delivery to surrounding tissue, allowing novel study of temporal growth factor release. The scaffold demonstrated that sequential delivery was key to EC and pericyte cell colocalization in maturing vessels. This platform can be applied to many other biomolecules and used to study the timing on their release and consequences in vivo.

Our laboratory has shown that the natural polymer dextran could be modified with various functional groups and crosslinked with polyethylene glycol diacrylate to form a biocompatible, hydrogel scaffold [70]. Dextran is a nontoxic polysaccharide made of linear $\alpha$-1,6-glycosidic linkages of D-glucose [70]. Subsequently, dextran's ability to promote angiogenesis was explored. The crosslinking density of dextran was decreased, which promoted tissue ingrowth, increased hydrogel swelling, and released more VEGF [71]. Immobilizing a combination of pro-angiogenic growth factors yielded effective formation of functional vessels. This study showed that such a platform could be a promising clinical therapy. Finally, we applied the dextran-polyethylene glycol diacrylate hydrogel platform to a murine burn wound model, as depicted in Figure 2 [72]. The hydrogel scaffold facilitated infiltration of angiogenic cells, which led to endogenous neovascularization and angiogenesis in the wound. The results showed an improved wound healing response and accelerated skin regeneration when compared with a bovine collagen and glycosaminoglycan matrix, which is a current treatment for burn wound injury. The dextran-polyethylene glycol diacrylate hydrogel could potentially provide an improved clinical solution to current treatments.

\section{Extracellular matrix-derived scaffolds}

ECM-derived scaffolds are optimal for cell attachment, growth, and signaling. They present ECM receptors and promote binding interactions that cells naturally encounter in the body. ECM-derived scaffolds are biocompatible since they have nontoxic degradation products. Researchers use various combinations of isolated proteins or fully decellularized ECM. Decellularized ECM can be deposited by a chosen cell type in vitro or extracted from tissue samples or intact organ sections $[1,9,17,63-66,73]$.

Decellularized ECM provides a scaffold that preserves the complex interactions of the numerous ECM components, which is difficult to mimic with polymer scaffolds [63-66]. Gilbert describes methods and difference in tissue and organ decellularization [65]. However, decellularized ECM scaffolds can present problems of immunogenicity, as it is hard to achieve complete decellularization. Cellular and tissue debris can be left over, allowing foreign material to initiate an immune response. Specifically for vascular regeneration, Koffler and colleagues used a biodegradable, acellular, Surgisis scaffold derived from porcine jejunum to create and study the integration of a vascularized muscle graft [73]. Part of the porcine small intestinal submucosa was taken 


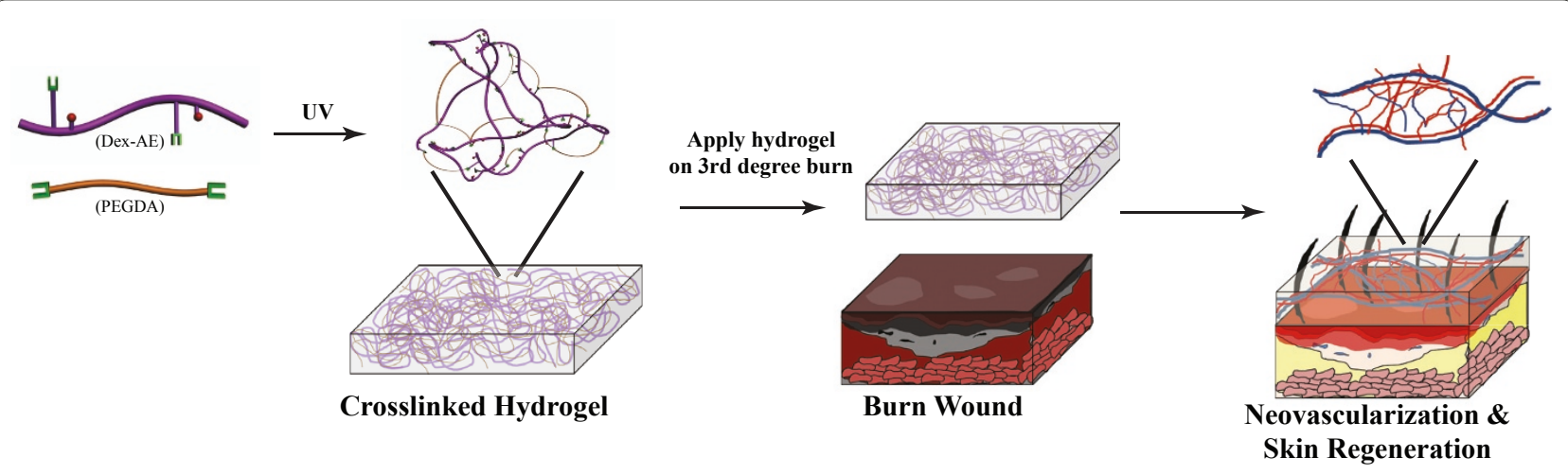

Figure 2. Example of a biodegradable scaffold platform to promote endogenous angiogenesis. Schematic of a dextran-polyethylene glycol diacrylate (PEGDA), three-dimensional, hydrogel scaffold promoting neovascularization, angiogenesis, and skin regeneration at a burn wound site. Reproduced with permission from Sun and colleagues [72].

from a pig and decellularized to create a small intestinal submucosa ECM-derived scaffold. The scaffold allowed for extended in vitro cell culture, vascularization, and muscle tissue organization, which resulted in improved anastomosis and vessel integration upon implantation. Overall, decellularization can provide an excellent approach for the generation of scaffolds as it preserves the physiological architecture, composition, and mechanics, which would support the formation of vasculature in vitro or the infiltration of vasculature to repopulate the scaffold in vivo [63-66]. However, there are still challenges that need to be addressed in tissue engineering, such as the source of organs for human usage, obtaining enough cells to repopulate the decellularized matrix, and maintaining cell viability and continued function.

Collagens, specifically collagen type I, are commonly isolated to create an ECM protein-derived gel. Stratman and colleagues created a platform using a collagen type I matrix to explore the role of cytokines and growth factors in tube morphogenesis and sprouting [25]. Using the collagen scaffold, Stratman and colleagues found that VEGF and FGF prime ECs to respond to stem cell factor, IL-3, and stromal-derived factor- $1 \alpha$ in serum-free conditions. Using this platform, these three cytokines were found to regulate EC morphogenesis and sprouting. This observation has major implications on current studies and clinical therapies, which apply pro-angiogenic factors. In a different study by $\mathrm{Au}$ and colleagues, EPCs were found to form dense and durable vessels with $10 \mathrm{~T} 1 / 2$ supporting cells in collagen-fibronectin gels [74]. Another ECM-derived component used to study angiogenesis is HA, a glycosaminoglycan. We used a modified HA hydrogel scaffold as a model for vascular network formation from human EPCs [62]. Vacuole and lumen formation, as well as branching and sprouting, were dependent on cell interactions with RGD peptides presented on the HA scaffold. Hanjaya-Putra and colleagues observed anastomosis with the murine host circulatory system in vivo, creating a controlled tube morphogenesis model in a completely synthetic HA scaffold.

Significant progress is being made with many scaffold materials in vascular engineering to promote and study vascular formation. Synthetic polymers provide high reproducibility and control over multiple parameters, allowing materials to be tuned for tissue-specific applications in the body. Natural polymers provide improved physiologic mimicry due to their biologically recognizable side groups and biocompatible properties. Decellularized ECM scaffolds give researchers the advantage of using organization and composition that naturally occur in the body, especially with the preservation of threedimensional architecture. Current biodegradable scaffold platforms have increased the understanding of vascular network formation and the key signaling pathways involved. These platforms have been mostly studied and assessed in vitro and on relatively small scales. To achieve a reproducible and reliable organ replacement therapy or ischemic tissue treatment, a deeper understanding of vascular functionality and durability in vivo needs to be explored. Altogether, platforms need to move from individual in vitro and small-scale animal trials to large animal models and human clinical studies in order to achieve pre-vascularize scaffolds and vascularization therapy of significant clinical relevance.

\section{Conclusion}

There is a significant clinical need to engineer platforms that can promote angiogenesis in damaged, ischemic tissue or can regulate angiogenesis in cases of vascular overgrowth. Tissue engineering has increased our understanding of processes in vascular network formation. Currently, biodegradable scaffolds created from synthetic or natural polymers and ECM-derived scaffolds hold 
promise in vitro and in animal studies. In many cases, however, scaffolds alone may not be enough to enable sufficient recruitment of host vasculature to support tissue regeneration in a clinically relevant manner. There is an increasing effort to understand the factors that control stem and progenitor cell homing and differentiation to vascular cell types, as well as the organization into vascular networks. One important aspect in the regulation of these processes is the physical interactions of cells with the scaffold prior to and after implantation. Presently, a quick off-the-shelf therapy to vascularize damaged tissue for any type of patient has yet to be achieved. Platforms need to be studied in preclinical, large animal models over extended time periods to truly gauge their clinical feasibility.

This article is part of a thematic series on Physical influences on stem cells edited by Gordana Vunjak-Novakovic. Other articles in the series can be found online at http://stemcellres.com/series/physical

\section{Abbreviations}

EC, endothelial cell; ECM, extracellular matrix; EPC, endothelial progenitor cell; ESC, embryonic stem cell; FGF, fibroblast growth factor; HA, hyaluronic acid; IL, interleukin; PCL, polycaprolactone; PLLA, poly-L-lactic acid; PLGA, poly(lacticco-glycolic acid); PSC, pluripotent stem cell; SMC, smooth muscle cell; VEGF, vascular endothelial growth factor.

\section{Competing interests}

The authors declare that they have no competing interests.

\section{Author details}

'Department of Biomedical Engineering, Johns Hopkins University, Baltimore, MD 21218, USA. ²Department of Chemical and Biomolecular Engineering, Johns Hopkins Physical Sciences - Oncology Center and Institute for NanoBioTechnology, Johns Hopkins University, Baltimore, MD 21218, USA.

Published: 24 January 2013

\section{References}

1. Hoenig MR: Tissue-engineered blood vessels: alternative to autologous grafts? Arterioscler Thromb Vasc Biol 2005, 25:1128-1134

2. Lesman $A$, Gepstein $L$, Levenberg $S$ : Vascularization shaping the heart Ann N Y Acad Sci2010, 1188:46-51.

3. Dean EW, Udelsman B, Breuer CK: Current advances in the translation of vascular tissue engineering to the treatment of pediatric congenital heart disease. Yale J Biol Med 2012, 85:229-238

4. Murphy SL, XU J, Kochanek KD: Deaths: preliminary data for 2010. Nat/ Vital Stat Rep 2012, 60:1-69.

5. World Health Organization: The Global Burden of Disease: 2004 Update. Geneva: WHO Press; 2008,

6. Heidenreich PA, Trogdon JG, Khavjou OA, Butler J, Dracup K, Ezekowitz MD, Finkelstein EA, Hong Y, Johnston SC, Khera A, Lloyd-Jones DM, Nelson SA, Nichol G, Orenstein D, Wilson PW, Woo YJ: Forecasting the future of cardiovascular disease in the United States: a policy statement from the American Heart Association. Circulation 2011, 123:933-944.

7. Dahl SLM, Kypson AP, Lawson JH, Blum JL, Strader JT, Li Y, Manson RJ, Tente WE, DiBernardo L, Hensley MT, Carter R, Williams TP, Prichard HL, Dey MS, Begelman KG, Niklason LE: Readily available tissue-engineered vascular grafts. Sci Trans/ Med 2011, 3:68ra69-68ra69.

8. Gong Z, Niklason LE: Blood vessels engineered from human cells. Trends Cardiovasc Med 2006, 16:153-156.

9. Zhang WJ, Liu W, Cui L, Cao Y: Tissue engineering of blood vessel. J Cell Mol Med 2007, 11:945-957.

10. Carmeliet $P$, Jain RK: Molecular mechanisms and clinical applications of angiogenesis. Nature 2011, 473:298-307.
11. Yoder MC, Ingram DA: Endothelial progenitor cell: ongoing controversy for defining these cells and their role in neoangiogenesis in the murine system. Curr Opin Hematol 2009, 16:269-273.

12. Ingber DE, Folkman J: Mechanochemical switching between growth and differentiation during fibroblast growth factor-stimulated angiogenesis in vitro: role of extracellular matrix. J Cell Biol 1989, 109:317-330.

13. Cheresh DA, Stupack DG: Regulation of angiogenesis: apoptotic cues from the ECM. Oncogene 2008, 27:6285-6298.

14. Davis GE: The development of the vasculature and its extracellular matrix a gradual process defined by sequential cellular and matrix remodeling events. Am J Physiol Heart Circ Physiol 2010, 299:H245-H247.

15. Davis GE, Koh W, Stratman AN: Mechanisms controlling human endothelial lumen formation and tube assembly in three-dimensional extracellular matrices. Birth Defects Res C Embryo Today 2007, 81:270-285.

16. Myers KA, Applegate KT, Danuser G, Fischer RS, Waterman CM: Distinct ECM mechanosensing pathways regulate microtubule dynamics to control endothelial cell branching morphogenesis. J Cell Biol 2011, 192:321-334.

17. Soucy PA, Romer LH: Endothelial cell adhesion, signaling, and morphogenesis in fibroblast-derived matrix. Matrix Biol 2009, 28:273-283.

18. Shin Y, Jeon JS, Han S, Jung G-S, Shin S, Lee S-H, Sudo R, Kamm RD, Chung S: In vitro 3D collective sprouting angiogenesis under orchestrated ANG-1 and VEGF gradients. Lab Chip 2011, 11:2175.

19. des RieuX A, Ucakar B, Mupendwa BPK, Colau D, Feron O, Carmeliet P, Préat V: 3D systems delivering VEGF to promote angiogenesis for tissue engineering. J Controlled Release 2011, 150:272-278.

20. Frontini MJ, Nong Z, Gros R, Drangova M, O'Neil C, Rahman MN, Akawi O, Yin $\mathrm{H}$, Ellis CG, Pickering JG: Fibroblast growth factor 9 delivery during angiogenesis produces durable, vasoresponsive microvessels wrapped by smooth muscle cells. Nat Biotechnol 2011, 29:421-427.

21. Tengood JE, Ridenour R, Brodsky R, Russell AJ, Little SR: Sequential delivery of basic fibroblast growth factor and platelet-derived growth factor for angiogenesis. Tissue Eng A 2011, 17:1181-1189.

22. Barreto-Ortiz SF, Gerecht S: Research highlights. Regen Med 2011, 6:551-554.

23. Singh S, Wu BM, Dunn JCY: The enhancement of VEGF-mediated angiogenesis by polycaprolactone scaffolds with surface cross-linked heparin. Biomaterials 2011, 32:2059-2069.

24. Singh S, Wu BM, Dunn JCY: Accelerating vascularization in polycaprolactone scaffolds by endothelial progenitor cells. Tissue Eng $A$ 2011, 17:1819-1830.

25. Stratman AN, Davis MJ, Davis GE: VEGF and FGF prime vascular tube morphogenesis and sprouting directed by hematopoietic stem cell cytokines. Blood 2011, 117:3709-3719.

26. Witmer AN, Vrensen GF, Van Noorden CJ, Schlinemann RO: Vascular endothelial growth factors and angiogenesis in eye disease. Prog Ret Eye Res 2003, 22:1-29.

27. Di Francescomarino S, Sciartilli A, Di Valerio V, Di Baldassarre A, Gallina S: The effect of physical exercise on endothelial function. Sports Med 2009, 39:797-812

28. Lu D, Kassab GS: Role of shear stress and stretch in vascular mechanobiology. J R Soc Interface 2011, 8:1379-1385.

29. Dvir T, Timko BP, Kohane DS, Langer R: Nanotechnological strategies for engineering complex tissues. Nat Nanotechnol 2011, 6:13-22.

30. Bajpai VK, Andreadis ST: Stem cell sources for vascular tissue engineering and regeneration. Tissue Eng B Rev 2012, 5:405-425

31. Reed DM, Foldes G, Harding SE, Mitchell JA: Stem cell derived endothelial cells for cardiovascular disease; a therapeutic perspective. Br J Clin Pharmacol 2012. doi: 10.1111/j.1365-2125.2012.04361.x. [Epub ahead of print]

32. Yoder MC, Mead LE, Prater D, Krier TR, Mroueh KN, Li F, Krasich R, Temm CJ, Prchal JT, Ingram DA: Redefining endothelial progenitor cells via clonal analysis and hematopoietic stem/progenitor cell principals. Blood 2007, 109:1801-1809.

33. Au P, Daheron LM, Duda DG, Cohen KS, Tyrrell JA, Lanning RM, Fukumura D, Scadden DT, Jain RK: Differential in vivo potential of endothelial progenitor cells from human umbilical cord blood and adult peripheral blood to form functional long-lasting vessels. Blood 2007, 111:1302-1305.

34. Joachim O, Sabine B, Birgitte J, Silvia F, Gerhard E, Martin B, Carsten W: Mesenchymal stem cells can be differentiated into endothelial cells in vitro. Stem Cells 2004, 22:377-384.

35. Kinner B, Zaleskas JM, Spector M: Regulation of smooth muscle actin expression and contraction in adult human mesenchymal stem cells. Exp Cell Res 2002, 278:72-83. 
36. Dong JD, Gu YQ, Li CM, Wang CR, Feng ZG, Qiu RX, Chen B, Li JX, Zhang SW, Wang ZG, Zhang J: Response of mesenchymal stem cells to shear stress in tissue-engineered vascular grafts. Acta Pharmacol Sin 2009, 30:530-536.

37. Nan W, Linlin M, Zhen Z, Junyun Z, Xuegang L, Yong J, Tongcun Z: Regeneration of smooth muscle cells from bone marrow: use of mesenchymal stem cells for tissue engineering and cellular therapeutics. In 3rd International Conference on Bioinformatics and Biomedical Engineering, iCBBE 2009: 2009. Beijing, China: 2009.

38. Hirschi KK, Rohovsky SA, D'Amore PA: PDGF, TGF- $\beta$, and heterotypic cell-cell interactions mediate endothelial cell-induced recruitment of $10 \mathrm{~T} 1 / 2$ cells and their differentiation to a smooth muscle fate. J Cell Bio/ 1998, 141:805-814.

39. Ball SG, Shuttleworth AC, Kielty CM: Direct cell contact influences bone marrow mesenchymal stem cell fate. Int J Biochem Cell Biol 2004, 36:714-727.

40. Takahashi K, Tanabe K, Ohnuki M, Narita M, Ichisaka T, Tomoda K, Yamanaka S: Induction of pluripotent stem cells from adult human fibroblasts by defined factors. Cell 2007, 131:861-872.

41. Thomson JA: Embryonic stem cell lines derived from human blastocysts. Science 1998, 282:1145-1147.

42. Choi K-D, Junying Y, Kim S-O, Giorgia S, William R, Maxim V, James T, Igor S: Hematopoietic and endothelial differentiation of human induced pluripotent stem cells. Stem Cells 2009, 27:559-567.

43. Vodyanik MA, Slukvin II: Hematoendothelial differentiation of human embryonic stem cells. Current Protoc Cell Biol 2007, Chapter 23:Unit 23.6.

44. Levenberg S, Golub JS, Amit M, Itskovitz-Eldor J, Langer R: Endothelial cells derived from human embryonic stem cells. Proc Natl Acad Sci U S A 2002, 99:4391-4396

45. Kaufman DS, Lewis RL, Hanson ET, Auerbach R, Plendl J, Thomson JA: Functional endothelial cells derived from rhesus monkey embryonic stem cells. Blood 2004, 103:1325-1332.

46. Gerecht S, Burdick JA, Ferreira LS, Townsend SA, Langer R, Vunjak-Novakovic G: Hyaluronic acid hydrogel for controlled self-renewal and differentiation of human embryonic stem cells. Proc Natl Acad SciU S A 2007, 104:11298-11303

47. Ferreira LS, Gerecht S, Shieh HF, Watson N, Rupnick MA, Dallabrida SM, VunjakNovakovic G, Langer R: Vascular progenitor cells isolated from human embryonic stem cells give rise to endothelial and smooth muscle-like cells and form vascular networks in vivo. Circ Res 2007, 101:286-294.

48. Gerecht-Nir S, Dazard JE, Golan-Mashiach M, Osenberg S, Botvinnik A, Amariglio N, Domany E, Rechavi G, Givol D, Itskovitz-Eldor J: Vascular gene expression and phenotypic correlation during differentiation of human embryonic stem cells. Dev Dyn 2005, 232:487-497.

49. Gerecht-Nir S, Ziskind A, Cohen S, Itskovitz-Eldor J: Human embryonic stem cells as an in vitro model for human vascular development and the induction of vascular differentiation. Lab Invest 2003, 83:1811-1820.

50. Wang L, Li L, Shojaei F, Levac K, Cerdan C, Menendez P, Martin T, Rouleau A, Bhatia M: Endothelial and hematopoietic cell fate of human embryonic stem cells originates from primitive endothelium with hemangioblastic properties. Immunity 2004, 21:31-41.

51. Wang ZZ, Au P, Chen T, Shao Y, Daheron LM, Bai H, Arzigian M, Fukumura D, Jain RK, Scadden DT: Endothelial cells derived from human embryonic stem cells form durable blood vessels in vivo. Nat Biotechnol 2007 25:317-318.

52. Nourse MB, Halpin DE, Scatena M, Mortisen DJ, Tulloch NL, Hauch KD, TorokStorb B, Ratner BD, Pabon L, Murry CE: VEGF induces differentiation of functional endothelium from human embryonic stem cells: implications for tissue engineering. Arterioscler Thromb Vasc Biol 30:80-89.

53. Cimato T, Beers J, Ding S, Ma M, McCoy JP, Boehm M, Nabel EG: Neuropilin-1 identifies endothelial precursors in human and murine embryonic stem cells before CD34 expression. Circulation 2009, 119:2170-2178.

54. James D, Nam HS, Seandel M, Nolan D, Janovitz T, Tomishima M, Studer L, Lee G, Lyden D, Benezra R, Zaninovic N, Rosenwaks Z, Rabbany SY, Rafii S: Expansion and maintenance of human embryonic stem cell-derived endothelial cells by TGF $\beta$ inhibition is Id1 dependent. Nat Biotech 2010, 28:161-166.

55. Sone M, Itoh H, Yamahara K, Yamashita JK, Yurugi-Kobayashi T, Nonoguchi A, Suzuki Y, Chao TH, Sawada N, Fukunaga Y, Miyashita K, Park K, Oyamada N, Sawada N, Taura D, Tamura N, Kondo Y, Nito S, Suemori H, Nakatsuji N, Nishikawa S, Nakao K: Pathway for differentiation of human embryonic stem cells to vascular cell components and their potential for vascular regeneration. Arterioscler Thromb Vasc Bio/ 2007, 27:2127-2134.

56. Taura D, Sone M, Homma K, Oyamada N, Takahashi K, Tamura N, Yamanaka S, Nakao K: Induction and isolation of vascular cells from human induced pluripotent stem cells - brief report. Arterioscler Thromb Vasc Biol 2009, 29:1 100-1103.

57. Tang ZCW, Liao W-Y, Tang ACL, Tsai S-J, Hsieh PCH: The enhancement of endothelial cell therapy for angiogenesis in hindlimb ischemia using hyaluronan. Biomaterials 2011, 32:75-86.

58. Singelyn JM, DeQuach JA, Seif-Naraghi SB, Littlefield RB, Schup-Magoffin PJ, Christman KL: Naturally derived myocardial matrix as an injectable scaffold for cardiac tissue engineering. Biomaterials 2009, 30:5409-5416.

59. Mima Y, Fukumoto S, Koyama H, Okada M, Tanaka S, Shoji T, Emoto M, Furuzono T, Nishizawa Y, Inaba M: Enhancement of cell-based therapeutic angiogenesis using a novel type of injectable scaffolds of hydroxyapatitepolymer nanocomposite microspheres. PLOS ONE 2012, 7:e35199.

60. Hou QP, De Bank PA, Shakesheff KM: Injectable scaffolds for tissue regeneration. J Mater Chem 2004, 14:1915-1923.

61. Lesman A, Koffler J, Atlas R, Blinder YJ, Kam Z, Levenberg S: Engineering vessel-like networks within multicellular fibrin-based constructs. Biomaterials 2011, 32:7856-7869.

62. Hanjaya-Putra D, Bose V, Shen YI, Yee J, Khetan S, Fox-Talbot K, Steenbergen C, Burdick JA, Gerecht S: Controlled activation of morphogenesis to generate a functional human microvasculature in a synthetic matrix. Blood 2011, 118:804-815

63. Petersen TH, Calle EA, Zhao L, Lee EJ, Gui L, Raredon MB, Gavrilov K, Yi T, Zhuang ZW, Breuer C, Herzog E, Niklason LE: Tissue-engineered lungs for in vivo implantation. Science 2010, 329:538-541.

64. Fukumitsu K, Yagi H, Soto-Gutierrez A: Bioengineering in organ transplantation: targeting the liver. Transplant Proc 2011, 43:2137-2138

65. Gilbert TW: Strategies for tissue and organ decellularization. J Cell Biochem 2012, 113:2217-2222.

66. Song JJ, Ott HC: Organ engineering based on decellularized matrix scaffolds. Trends Mol Med 2011, 17:424-432.

67. Levenberg S, Rouwkema J, Macdonald M, Garfein ES, Kohane DS, Darland DC, Marini R, van Blitterswijk CA, Mulligan RC, D'Amore PA, Langer R: Engineering vascularized skeletal muscle tissue. Nat Biotechnol 2005, 23:879-884.

68. Lesman A, Habib M, Caspi O, Gepstein A, Arbel G, Levenberg S, Gepstein L: Transplantation of a tissue-engineered human vascularized cardiac muscle. Tissue Eng Part A 2010, 16:115-125.

69. Caspi O, Lesman A, Basevitch Y, Gepstein A, Arbel G, Habib IH, Gepstein L, Levenberg S: Tissue engineering of vascularized cardiac muscle from human embryonic stem cells. Circ Res 2007, 100:263-272.

70. Sun G, Shen Y-I, Ho CC, Kusuma S, Gerecht S: Functional groups affect physical and biological properties of dextran-based hydrogels. J Biomed Mater Res A 2010, 93:1080-1090.

71. Sun G, Shen Y-I, Kusuma S, Fox-Talbot K, Steenbergen CJ, Gerecht S: Functional neovascularization of biodegradable dextran hydrogels with multiple angiogenic growth factors. Biomaterials 2011, 32:95-106.

72. Sun G, Zhang X, Shen YI, Sebastian R, Dickinson LE, Fox-Talbot K, Reinblatt M, Steenbergen C, Harmon JW, Gerecht S: Dextran hydrogel scaffolds enhance angiogenic responses and promote complete skin regeneration during burn wound healing. Proc Natl Acad SciU S A 2011, 108:20976-20981.

73. Koffler J, Kaufman-Francis K, Shandalov Y, Egozi D, Pavlov DA, Landesberg A, Levenberg S: Improved vascular organization enhances functional integration of engineered skeletal muscle grafts. Proc Natl Acad Sci U S A 2011, 108:14789-14794

74. Au P, Daheron LM, Duda DG, Cohen KS, Tyrrell JA, Lanning RM, Fukumura D, Scadden DT, Jain RK: Differential in vivo potential of endothelial progenitor cells from human umbilical cord blood and adult peripheral blood to form functional long-lasting vessels. Blood 2008, 111:1302-1305.

\section{doi:10.1186/scrt156}

Cite this article as: Serbo JV, Gerecht S: Vascular tissue engineering: biodegradable scaffold platforms to promote angiogenesis. Stem Cell Research \& Therapy 2013, 4:8. 